\title{
P3HT:PCBM Incorporated with Silicon Nanoparticles as Photoactive Layer in Efficient Organic Photovoltaic Devices
}

\author{
Shang-Chou Chang, ${ }^{1}$ Yu-Jen Hsiao, ${ }^{2}$ and To-Sing $\mathrm{Li}^{1}$ \\ ${ }^{1}$ Department of Electrical Engineering, Kun Shan University, Da-Wan Road, Tainan City 71003, Taiwan \\ ${ }^{2}$ National Nano Device Laboratories, Tainan City 74147, Taiwan \\ Correspondence should be addressed to Shang-Chou Chang; jchang@mail.ksu.edu.tw
}

Received 17 October 2013; Revised 28 November 2013; Accepted 1 December 2013

Academic Editor: Sheng-Po Chang

Copyright (c) 2013 Shang-Chou Chang et al. This is an open access article distributed under the Creative Commons Attribution License, which permits unrestricted use, distribution, and reproduction in any medium, provided the original work is properly cited.

Silicon nanoparticles doped poly(3-hexylthiophene) and [6,6]-phenyl C61-butyric acid methyl ester blends (P3HT:PCBM: Si NP) have been produced as the photoactive layer of organic photovoltaic devices (OPVs). The silicon nanoparticles' size is between 80 and $100 \mathrm{~nm}$ checked by transmission electron microscope (TEM). The $0.35 \mathrm{wt} \% \mathrm{Si}$ NP doping OPVs exhibit higher power conversion efficiency (PCE) than other OPVs. The PCE of the OPVs increases from 3.01\% to 3.38\% mainly due to increasing short-circuit current density from 8.38 to $9.48 \mathrm{~mA} / \mathrm{cm}^{2}$, while the open-circuit voltage remains the same. The Si NP can provide extra exciton separation and electron pathways in hybrid solar cells.

\section{Introduction}

Solar energy has been greatly cared as a renewable energy source. Organic photovoltaic devices are attractive low-cost alternative compared with thin-film solar cells (single-polycrystalline and amorphous thin films) and compound-based solar cells (copper indium gallium (di)selenide (CIGS), GaAs, $\mathrm{CdTe}$ ). They are easily produced and large-area modules can be made with roll-to-roll process.

The PCE of OPVs with poly(3-hexylthiophene) (P3HT) and [6,6]-phenyl C61-butyric acid methyl ester (PCBM) blend as the photoactive layer is high compared with that of other OPVs so far. The P3HT provides the pi-orbit electron excitation during the photovoltaic process [1]. The PCBM usually acts an electron transport material in polymer solar cells.

The PCE of OPVs under AM 1.5 conditions has exceeded $7.4 \%$ [2]. The PCE of OPVs can be improved by doping nanomaterials like single-walled carbon nanotubes [3], multiwalled carbon nanotubes [4], nanodiamond [5], $\mathrm{Fe}_{3} \mathrm{O}_{4}$ magnetic nanoparticles [6], and $\mathrm{ZnO}$ nanorods [7]. Nanomaterials, which can be used to make superstrong metals [8], have become popular as semiconductor nanocrystals and solar cell materials due to their high surface to volume ratio, quantum confinement [9], quantum size [10], and small size effect [5].

Silicon, which has been successfully applied in solar cell and microelectronics industry, is a potential candidate for polymer-nanomaterials solar cells owing to its abundance, nontoxicity, and strong ultraviolet absorption. Doping Si $\mathrm{NP}$ into polymer materials acting as the photoactive layer of OPVs may increase the electron collection rate in the mixture. This work investigates the effect of employing P3HT:PCBM:Si NP as photoactive layer in OPVs on their electrical and optical properties.

\section{Experimental Procedure}

Organic photovoltaic devices were fabricated on indium tin oxide (ITO) coated glass substrates. The ITO glass substrate was ultrasonic cleaned in acetone, isopropanol, and deionized water in sequence to remove contaminants, then dried by nitrogen. After that, the ITO glass substrates were oxygen plasma cleaned by an inductively coupled plasma system to make the ITO surface hydrophilic. A 40-nm-thick layer of poly(3,4-ethylenedioxythiophene) poly(styrenesulfonate) (PEDOT:PSS, Baytron P 4083) was spin-coated onto the ITO 
glass substrate with $2600 \mathrm{rpm}$ spin speed and then baked at $120^{\circ} \mathrm{C}$ for 30 minutes.

The photoactive layer was made of P3HT:PCBM:Si NP dissolved in 1,2-dichlorobenzene. The P3HT (FEM. Inc.) and PCBM (Nano-C) were 10:8 wt \% in proportion. The Si NP (ITRI Taiwan) of size $80-100 \mathrm{~nm}$ prepared by the vibrating milled solid-state reaction was used. Various concentration of Si NP was processed in P3HT:PCBM:Si NP. The P3HT:PCBM:Si NP blend film was spin-coated on ITO glass substrate with $1500 \mathrm{rpm}$ spin speed in a glove box. The P3HT:PCBM:Si NP blend film was then annealed at $120^{\circ} \mathrm{C}$ for $10 \mathrm{~min}$ to reduce contact resistance of electrodes. Finally, a 120 -nm-thick $\mathrm{Ca} / \mathrm{Al}$ electrode was deposited onto the P3HT:PCBM:Si NP blend film through a shadow mask by thermal evaporation. The devices were sealed by a glass slide coated with UV glue after UV light irradiation. The device area was about $0.04 \mathrm{~cm}^{2}$. Subsequently, the P3HT:PCBM:Si NP blend film was measured with TEM. The current densityvoltage measurements were obtained by using a source meter (Keithley, 2410) and a solar simulator (TELTEC) with an AM 1.5 illumination and intensity of $100 \mathrm{~mW} \mathrm{~cm}^{-2}$. For external quantum efficiency (EQE) measurements, a xenon lamp (Oriel, 66150, $75 \mathrm{~W}$ ) was used as the light source, and a chopper and lock-in amplifier were used for phase-sensitive detection. Absorption spectra were measured by an optical spectrometer (Hitachi, U-4100).

\section{Results and Discussion}

Figure 1 shows the device structure of the produced OPVs, in which P3HT:PCBM:Si NP is the photoactive layer of the device. Calcium was added to the metal electrodes to improve the fill factor (FF) and the open-circuit voltage $\left(V_{\mathrm{oc}}\right)$ [11]. The organic layer of anhydrous molecular residues must be controlled because of calcium oxidizes if it is exposed to oxygen and moisture [12]. The spherical morphology of $\mathrm{Si}$ NP was clearly observed, as evidenced from TEM images in Figure 2. It possesses a uniform dispersion with average diameter about 80 100 $\mathrm{nm}$.

A previous study found that the crystallization, interchain interaction, and phase separation of photoactive layers depend on the composite mixture and its doping concentration of nanomaterials. Similar results were obtained for P3HT:PCBM:nanodiamond layers with various nanodiamond concentrations [5]. Phase segregation increases with increasing contact area between aggregated particles. Therefore, doping Si nanoparticles may cause phase separation with high roughness for the OPVs. The Si NP plays an active role in exciton dissociation due to its greater surface-area-to-volume ratio and wider band gap [13]. Furthermore, short-circuit current density $\left(J_{\mathrm{sc}}\right)$ increases with concentration of Si NP. However, the current could be limited by a bottleneck in the hole transport material, $\mathrm{P} 3 \mathrm{HT}$, or the efficiency of exciton dissociation could decrease rapidly when the concentration of Si NP reaches a certain limit.

The photovoltaic characteristics, namely, $V_{\mathrm{oc}}, J_{\mathrm{sc}}$, fill factor (FF), and PCE, for OPVs with different concentration of

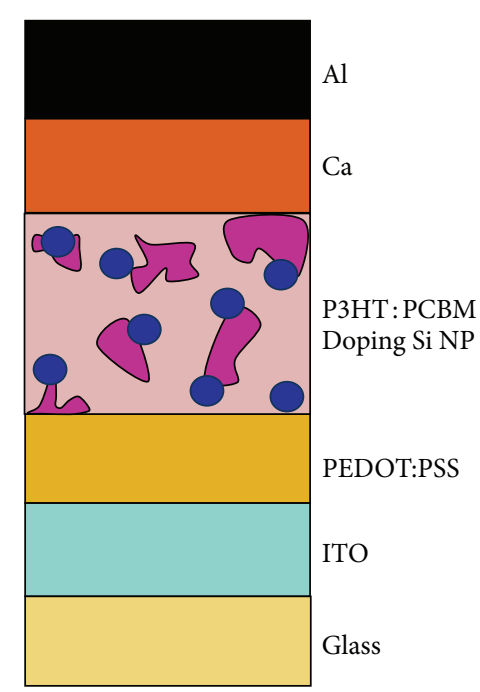

Figure 1: The structure of the P3HT:PCBM:Si NP organic photovoltaic device.

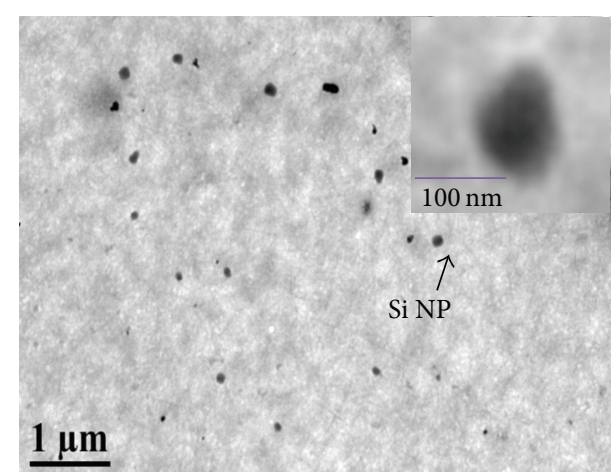

Figure 2: TEM micrograph of P3HT:PCBM:0.35 wt \%Si NP.

TABLE 1: The photovoltaic characteristics, namely $V_{\mathrm{oc}}, J_{\mathrm{sc}}, \mathrm{FF}$, and PCE, for P3HT:PCBM:Si NP OPVs with various Si NP concentration.

\begin{tabular}{lcccc}
\hline $\begin{array}{l}\text { Concentration } \\
\text { of Si NP (wt\%) }\end{array}$ & $V_{\text {oc }}(\mathrm{V})$ & $J_{\text {sc }}\left(\mathrm{mA} / \mathrm{cm}^{2}\right)$ & FF & PCE (\%) \\
\hline 0 & 0.599 & 8.38 & 60.12 & 3.01 \\
0.07 & 0.599 & 8.54 & 61.08 & 3.12 \\
0.35 & 0.599 & 9.48 & 60.42 & 3.38 \\
0.70 & 0.649 & 6.56 & 53.17 & 2.27 \\
\hline
\end{tabular}

doping Si NP, are given in Table 1. Figure 3 shows the currentvoltage $(I-V)$ characteristics of OPVs measured under an illumination intensity of $100 \mathrm{Mw} \mathrm{cm}^{-2}$. The $J_{\mathrm{sc}}$ and PCE in OPVs rise with Si NP doping concentration till $0.35 \mathrm{wt} \%$. The $0.35 \mathrm{wt} \% \mathrm{Si}$ NP doping into the photoactive layer results in an increment in $J_{\mathrm{sc}}$ from 8.38 to $9.48 \mathrm{~mA} \mathrm{~cm}^{-2}$. The PCE of the OPVs grows from 3.01 to $3.38 \%$. The Si NP doping increases the donor/acceptor interface area for charge separation and shortens the electron transfer path in P3HT:PCBM, which improves the $J_{\mathrm{sc}}$ and PCE. However, the PCE decreases when 


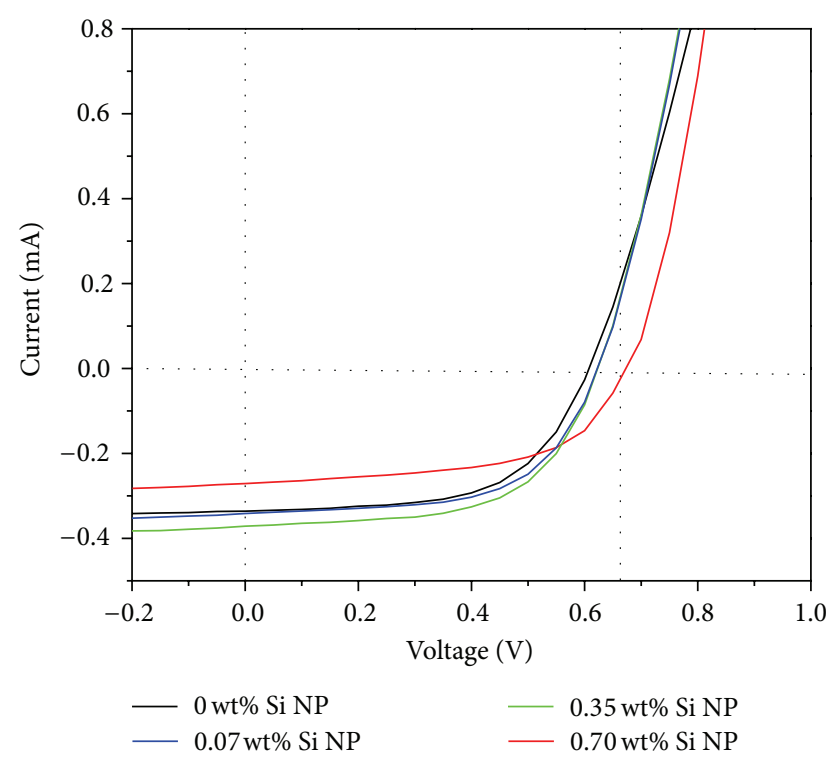

FIgURE 3: The current-voltage $(I-V)$ characteristics of for P3HT:PCBM:Si NP OPVs with various Si NP concentration.

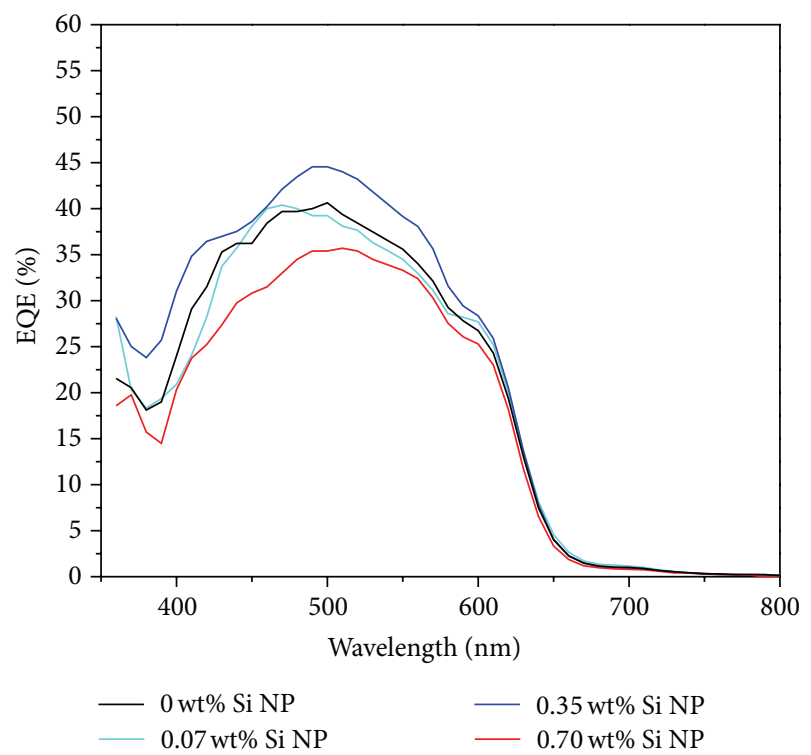

FIgure 4: The EQE spectra for P3HT:PCBM:Si NP OPVs with various Si NP concentration.

the concentration of Si NP exceeds $0.35 \mathrm{wt} \%$, probably due to rising leakage current [14].

The EQE spectra for OPVs with different concentration of doping Si NP are shown in Figure 4. Although all EQE spectra are similar in shape, the value of EQE spectra for the OPVs containing $0.35 \mathrm{wt} \% \mathrm{Si} \mathrm{NP}$ is the highest among those of all OPVs. For example, the EQE maximum for the OPVs containing $0.35 \mathrm{wt} \% \mathrm{Si} \mathrm{NP}$ is $44.5 \%$ at $500 \mathrm{~nm}$ whereas that containing $0.7 \mathrm{wt} \% \mathrm{Si} \mathrm{NP}$ is $35.4 \%$ at the same wavelength. The difference is due to an increased rate of electron collection in the OPVs. No obvious change in optical absorption spectra was observed when the active layer was blended with P3HT:PCBM:Si NP. However, the peak wavelengths at approximately $340 \mathrm{~nm}$ may attribute to the PCBM band and those at approximately $400-650 \mathrm{~nm}$ attribute to the pristine $\mathrm{P} 3 \mathrm{HT}$ band in the absorption spectra [15].

\section{Conclusion}

The OPVs with P3HT:PCBM:Si NP as the photoactive layer have been produced. The Si NP is well dispersed into the P3HT:PCBM polymer matrix. Doping Si NP increases the $J_{\text {sc }}$ in OPVs, thus increasing PCE via faster electron collection rate. The highest measured $\mathrm{PCE}$ is $3.38 \%$, corresponding to OPVs containing $0.35 \mathrm{wt} \% \mathrm{Si} \mathrm{NP}$ among those of all OPVs. The Si NP can provide extra exciton separation and electron pathways in OPVs, which increases the $J_{\text {sc }}$ and PCE.

\section{Acknowledgment}

The authors would like to thank the National Science Council of Taiwan for financially supporting this research under Grant NSC 100-2628-E-151-003-MY3 and NSC 102-2221-E168-037.

\section{References}

[1] H. S. Nalwa, Handbook of Organic Conductive Molecules and Polymers, Volume 3, Conductive Polymers: Spectroscopy and Physical Properties, Wiley, 1997.

[2] Y. Liang, Z. Xu, J. Xia et al., "For the bright future-bulk heterojunction polymer solar cells with power conversion efficiency of 7.4\%," Advanced Materials, vol. 22, no. 20, pp. E135-E138, 2010.

[3] R. K. Singh, J. Kumar, A. Kumar, V. Kumar, R. Kant, and R. Singh, "Poly(3-hexylthiophene): functionalized single-walled carbon nanotubes: $(6,6)$-phenyl-C61-butyric acid methyl ester composites for photovoltaic cell at ambient condition," Solar Energy Materials and Solar Cells, vol. 94, no. 12, pp. 2386-2394, 2010.

[4] M. Wu, Y. Lin, S. Chen et al., "Enhancing light absorption and carrier transport of P3HT by doping multi-wall carbon nanotubes," Chemical Physics Letters, vol. 468, no. 1-3, pp. 64$68,2009$.

[5] Y. Hsiao, T. Fang, L. Ji, Y. Lee, and B. Dai, "Size effect of nanodiamonds on P3HT:PCBM heterojunction solar cells," Electrochemistry Communications, vol. 18, no. 1, pp. 4-7, 2012.

[6] W. Zhang, Y. Xu, H. Wang, C. Xu, and S. Yang, " $\mathrm{Fe}_{3} \mathrm{O}_{4}$ nanoparticles induced magnetic field effect on efficiency enhancement of P3HT:PCBM bulk heterojunction polymer solar cells," Solar Energy Materials and Solar Cells, vol. 95, no. 10, pp. 2880-2885, 2011.

[7] S. V. Bhat, A. Govindaraj, and C. N. R. Rao, "Hybrid solar cell based on P3HT-ZnO nanoparticle blend in the inverted device configuration," Solar Energy Materials and Solar Cells, vol. 95, no. 8, pp. 2318-2321, 2011.

[8] R. Valiev, "Materials science: nanomaterial advantage," Nature, vol. 419, no. 6910, pp. 887-889, 2002.

[9] S. Q. Feng, D. P. Yu, H. Z. Zhang, Z. G. Bai, and Y. Ding, “The Growth mechanism of silicon nanowires and their quantum confinement effect," Journal of Crystal Growth, vol. 209, no. 2-3, pp. 513-517, 2000. 
[10] A. C. Varonides, "Quantum size effects in amorphous $\mathrm{Si}$ superlattice solar cells," Renewable Energy, vol. 33, no. 2, pp. 273-276, 2008.

[11] Q. Liu, Z. Liu, X. Zhang et al., "Polymer photovoltaic cells based on solytion-processable graphene and P3HT," Advanced Functional Materials, vol. 19, no. 6, pp. 894-904, 2009.

[12] B. Paci, A. Generosi, V. R. Albertini, P. Perfetti, R. de Bettignies, and C. Sentein, "Time-resolved morphological study of organic thin film solar cells based on calcium/aluminium cathode material," Chemical Physics Letters, vol. 461, no. 1-3, pp. 77-81, 2008.

[13] U. R. Kortshagen, C. Liu, and Z. C. Holman, "Hybrid solar cells from P3HT and silicon nanocrystals," Nano Letters, vol. 9, no. 1, pp. 449-452, 2009.

[14] Y. Liu, C. Liu, and Y. Liu, "Investigation on fluorescence quenching of dyes by graphite oxide and graphene," Applied Surface Science, vol. 257, no. 13, pp. 5513-5518, 2011.

[15] G. Li, Y. Yao, H. Yang, V. Shrotriya, G. Yang, and Y. Yang, "Solvent annealing effect in polymer solar cells based on poly(3hexylthiophene) and methanofullerenes," Advanced Functional Materials, vol. 17, no. 10, pp. 1636-1644, 2007. 

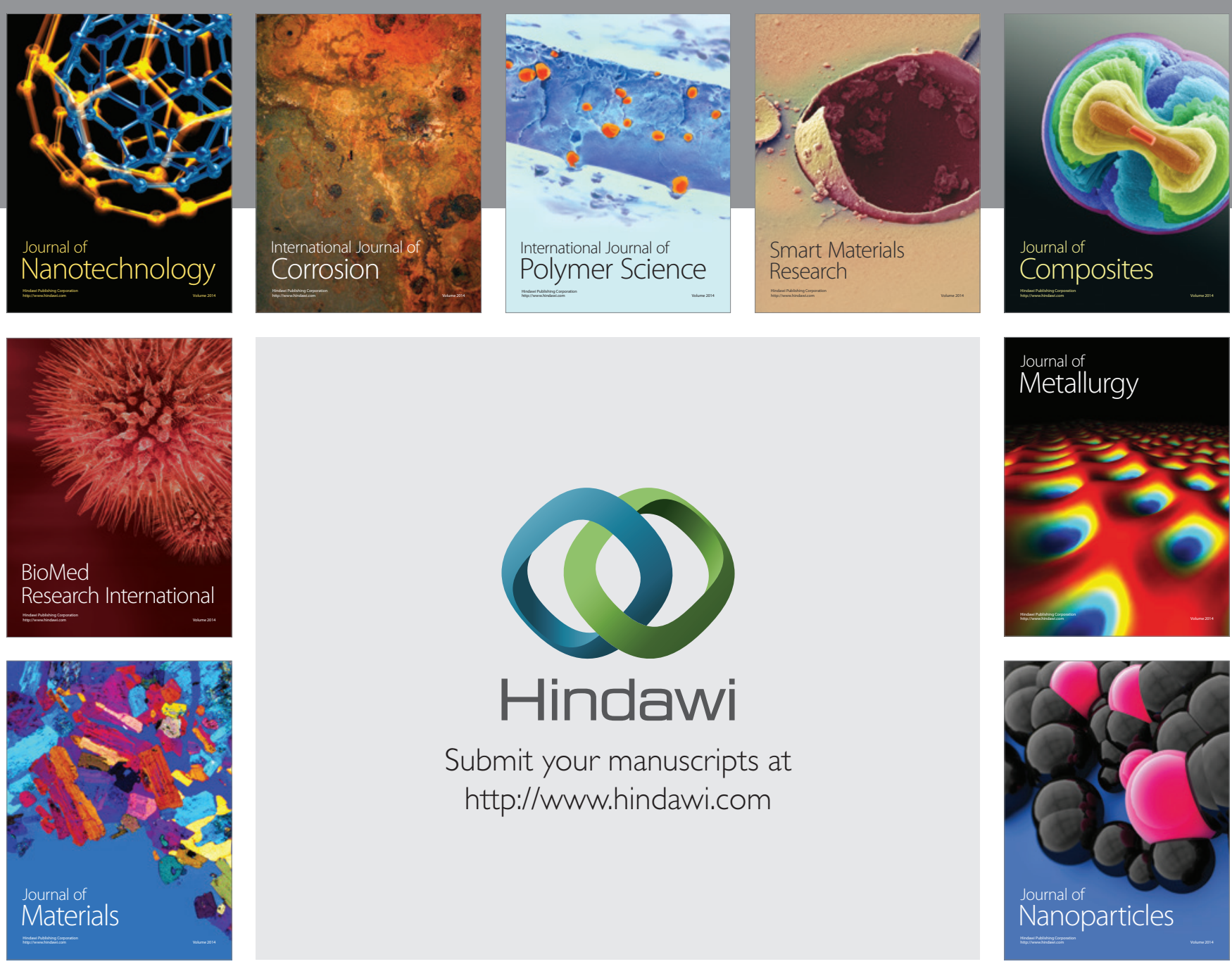

Submit your manuscripts at http://www.hindawi.com
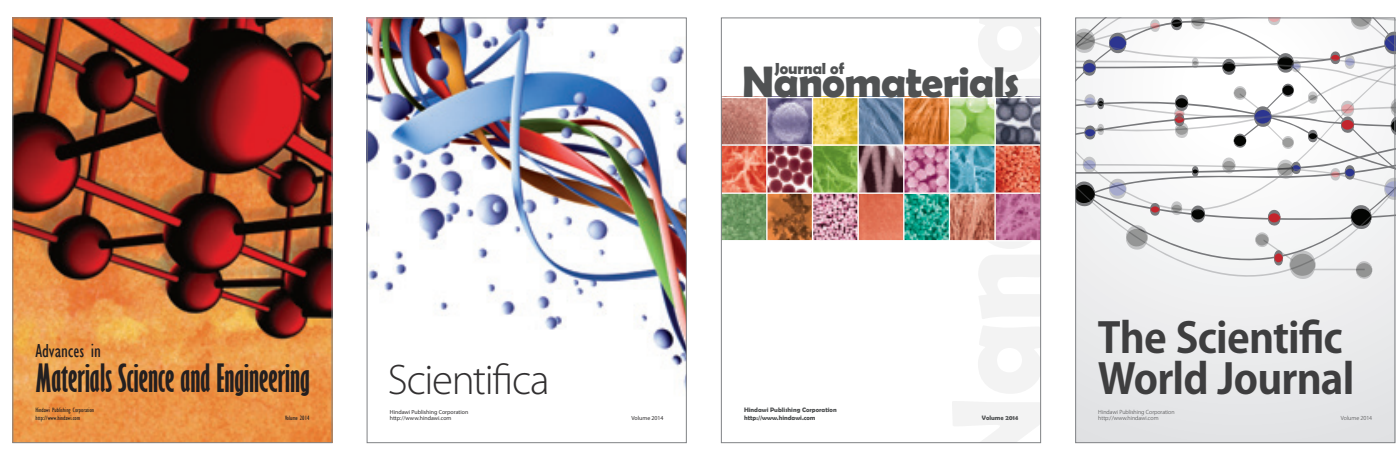

\section{The Scientific World Journal}
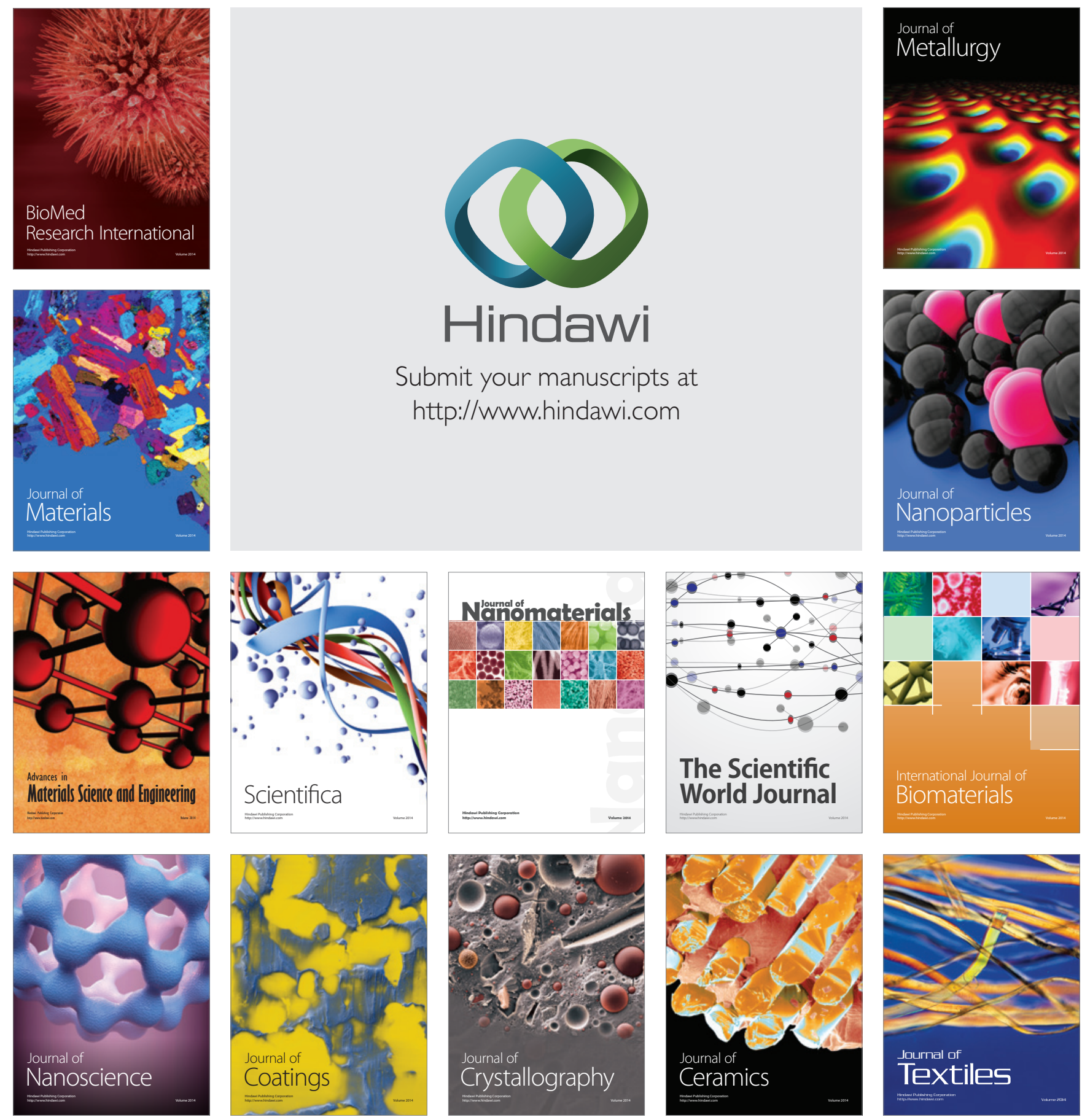